\title{
The (Limited) Space for Justice in Social Animals
}

\section{Journal Article}

Author(s):

Christen, Markus; Glock, Hans-Johann

Publication date:

2012-09

Permanent link:

https://doi.org/10.3929/ethz-b-000055579

Rights / license:

In Copyright - Non-Commercial Use Permitted

Originally published in:

Social Justice Research 25(3), https://doi.org/10.1007/s11211-012-0163-x 


\title{
The (Limited) Space for Justice in Social Animals
}

\author{
Markus Christen • Hans-Johann Glock
}

Published online: 23 August 2012

(C) Springer Science+Business Media, LLC 2012

\begin{abstract}
While differentialists deny that non-linguistic animals can have a sense of justice, assimilationists credit some animals with such an advanced moral attitude. We approach this debate from a philosophical perspective. First, we outline the history of the notion of justice in philosophy and how various facets of that notion play a role in contemporary empirical investigations of justice among humans. On this basis, we develop a scheme for the elements of justice-relevant situations and for criteria of justice that should be fruitful in studying both humans and animals. Furthermore, we investigate the conceptual connections between a sense of justice, on the one hand, and various other mental powers, on the other, and indicate which of the latter may be beyond the ken of animals. Next, we consider recent empirical research on justicerelated phenomena in animals. We argue for an intermediate position: While animals can at least in principle satisfy some preconditions of justice (intentional action, rulefollowing), others are problematic, notably possessing a notion of desert. A space for justice in social animals exists, yet it is rather limited compared to the rich cultures of justice in humans. Finally, we reflect on some actual or alleged implications of research on animal justice. As regards justice in humans, one should avoid a simplistic image of "natural justice" as boiling down to equal allocation of goods. As regards justice for animals, one should be weary of the contractualist assumption that only those capable of justice themselves are deserving of "just" treatment.
\end{abstract}

\section{Christen}

Institute of Biomedical Ethics, University of Zurich, Pestalozzistrasse 24, 8032 Zürich, Switzerland

\section{Christen (ه)}

Psychology Department, University of Notre Dame, 227 Haggar Hall, 46556 Notre Dame, IN, USA e-mail: markus@brainform.com; christen@ethik.uzh.ch

\section{H.-J. Glock}

Institute of Philosophy, University of Zurich, Zürichbergstrasse 43, 8044 Zürich, Switzerland e-mail: glock@philos.uzh.ch 
Keywords Justice - Animals · Differentialism - Assimilationism · Fairness · Inequity aversion · Desert · Norms · Contractualism

\section{Whence the Interest in "Justice" in Animals?}

Do some animals possess anything like a "sense of justice?" Might there even be animal societies in which "justice rolls down like water and righteousness like a mighty stream" (Martin Luther King)? There are two opposing answers to such questions. On the one hand, even moderate "differentialists" will be skeptical about applying a complex concept like "justice," which is deeply interwoven in human social organization, including institutions like the law, to non-linguistic "beasts." Thus, Aristotle influentially denied that animals have a sense of justice on the grounds that they lack speech (Aristotle 1984a, Politics 1.2, 1253a14-18). On the other hand, among the opposing "assimilationists," some have been willing to credit animals even with an advanced moral attitude like a sense of justice. ${ }^{1}$ Ironically, from ancient Greece down to the Middle Ages, this was sometimes regarded as a rationale not for improving the lot of animals, but rather for punishing them for various misdemeanors (Sorabji 1994, pp 119-121).

Differentialism is not confined to philosophy. Until about 20 years ago, most behavioral scientists would have regarded the idea of justice among animals as an "anthropomorphic" projection of uniquely human characteristics onto animals. However, the rise of cognitive ethology brought about a sea-change in favor of assimilationism. That tendency has extended to moral attitudes like altruism and justice (e.g., de Waal 1996). What is more, many philosophers have taken an "empirical turn" (Knobe and Nichols 2008; Musschenga 2005), e.g., by using experimental methods to investigate philosophical claims. This has included moral philosophy and has prepared the ground for an increasing interest in empirical research on justice and other aspects of morality. Finally, this interest has included the evolution of morality (Kitcher 2011) as well as recent research on pro-sociality, social emotions, and justice/fairness in animals. In this context, both ethologists and philosophers have made bold claims about the moral lives of animals in general and "wild justice" in particular (Bekoff and Pierce 2009). The question here is not whether animals are objects of justice considerations, a question of animal welfare. It is rather whether animals are subjects of moral attitudes in general and a sense of justice in particular, and whether they can display these attitudes when interacting with conspecifics or human care-givers. In this paper, when we write of "animal justice," we refer to the issue of justice in animals rather than that of justice for animals.

It is not our ambition here to solve normative issues (e.g., "is the act $\mathrm{X}$ or the distribution of good Y just?"). Rather, we are concerned with the question of what

\footnotetext{
1 This useful terminology for contrasting those maintaining that the mental or moral differences between humans and animals are qualitative and those that insist that they are merely a matter of degree derives from Brandom (2000, pp 2-3).
} 
phenomena should count as part of the realm of justice and what competences are needed for entertaining beliefs about justice and for acting in a just way. Studies of animals have a methodological value. Finding methods for investigating animal behaviors that may be related to justice requires analyzing these terms in a specific way, namely with a view to developing experimental paradigms for agents ${ }^{2}$ that do not possess human conceptual and linguistic abilities, yet nevertheless display advanced social skills and competences. Furthermore, assessing whether there is a legitimate notion of justice that can be applied to animal behavior is a task of conceptual clarification, and hence within the remit of philosophy.

The philosopher's task with respect to the study of justice in animals is threefold: Firstly, to outline the various facets of the notion of justice (See the "Justice in Philosophy" and "Assessing Justice in Human Societies" sections) in order to investigate which understanding of justice may be fruitful in animal studies (See the "A Scheme for Analyzing Justice" and "Analyzing the Animal Justice Debate" sections). Secondly, to investigate the conceptual connections between justice and a sense of justice, on the one hand, and various other mental phenomena, on the other (See the "Justice and Mental Capacities" section). For, the capacity for various dimensions of justice may presuppose other mental capacities that animals cannot be credited with. Both tasks require conceptual analysis in a suitably liberal sense of the label (Glock 2013) and also drawing on the history of ideas. Thirdly, philosophers should keep in mind that animal research has a potential to change our understanding of justice, in particular by accentuating specific aspects (e.g., distributive justice). It also has the potential for wider cultural effects. For example, research on chimpanzee warfare published some years ago disseminated in the public sphere as evidence that humans are martial "by nature" (Fry 2005). Research on justice in animals may have similar effects, e.g., by promoting a specific understanding of justice within society (reducing it to equal distribution) at the expense of other aspects of justice.

Our contribution deals with all three aspects - the facets of the notion of justice, the conceptual connections between a capacity for justice and other mental capacities, and the consequences of justice research in animals for our understanding of justice within society. Our focus is on the limitations of "animal justice" given the complexity of justice in humans. Firstly, many of the elements of justice exist only in rudimentary forms; secondly, there are conceptual and methodological difficulties in ascribing to animals intentional states and rules sophisticated enough to underpin, e.g., a notion of desert. Thirdly, the experiments on inequity aversion in animals suggest that the latter is almost exclusively self-regarding and hence does not qualify as a genuine sense of justice.

Our contribution is structured as follows: In the following section, we will briefly sketch the main strands of philosophical reflections on justice from a historical perspective. In the "Assessing Justice in Human Societies" section, we outline some major empirical research on humans in order to demonstrate that the complexity of

\footnotetext{
${ }^{2}$ We use the term agent in a broad sense to apply to any creature that behaves in a purposeful manner. For a defense of the idea that higher animals are capable of acting, and of acting for reasons, see Glock (2009).
} 
the concept of justice is not an artifact of philosophical theorizing, but reflects human social practice. These two sections serve as brief overviews for readers who are not familiar with current discussions of justice in philosophy and psychology/ sociology. The "A Scheme for Analyzing Justice" section presents a conceptual scheme that delineates the various facets of justice based on classifications in philosophy and social psychology. Based on this scheme, we reflect on what elements of justice-relevant situations and what criteria for considerations about justice might be present in animal societies. In the "Justice and Mental Capacities" section, we discuss which mental capacities we consider as relevant to the question of whether "justice" and its cognates can be applied to animal behavior, and indicate why some of them seem beyond the ken for animals. In the "Analyzing the Animal Justice Debate" section, we will review and comment on the current research on justice in animals based on the previous analyses. Finally, in the "Broader Implications of Animal Justice Research" section, we briefly speculate on the effect of research on justice in animals on the understanding of justice in modern human society.

\section{Justice in Philosophy}

The term "justice" has fuzzy boundaries and is related to other important moral terms, e.g., equality, fairness, impartiality, legitimacy, solidarity, as well as to honesty and integrity. Sometimes, "justice" is treated as a synonym for "morality" per se. This plurality of meaning becomes intelligible given the history of the idea. In the civilizations of the ancient Middle East, the notion of justice was very broad and involved the idea of a "balance" between the metaphysical order and the system of rules in place-a "cosmic justice" (Horn and Scarano 2002: Introduction). The Greek sophists of the fifth century B.C. critically assessed the "origins of what we call just," reflecting the problem of cultural relativism that emerged after having observed that other civilizations had different moral standards. They posed a question that resonates through the history of our topic, namely whether justice has a "natural source" (physis) independent of variable human practices or whether it is the result of a human setting (thesis), i.e., results from a specific cultural tradition.

Many Greek philosophers adopted a broad understanding of justice and regarded it as equivalent to morality in general. Plato in the Republic treats justice as an overarching virtue of individuals and of societies. The Greek terminus dikaiosyne, which is usually translated as "justice," characterizes both the social behavior of the individual and the moral state of the political system (Vlastos 1971). Nevertheless, justice is mostly understood as a virtue of persons, such that a "just person" is someone who wants the Good to happen, i.e., justice is treated as equivalent to moral virtue.

An influential distinction was drawn by Aristotle. He distinguished a more general conception of justice as a synonym for virtue (the just man being the virtuous or good man) and a more specific conception that refers to the allocation of goods (Aristotle 1984b, Nicomachean Ethics, Book V). The latter anticipates the modern usage of "justice," although it still refers to the virtue of a person. 
Furthermore, Aristotle distinguished two types of justice in its allocation sense: distributive justice and retributive justice. Distributive justice concerns the specific allocation of goods, like the partitioning of a cake and rewards for good behavior. Retributive justice concerns compensations for any disturbance of the order of things, notably punishment.

The modern age brought about a major shift, a focus on justice in society and with respect to the political order rather than the virtue of individuals. At the same time, the question persisted whether justice is an external principle that legitimates a specific legal system, or whether justice is generated by a legal system, the legitimation of which is founded by other principles (an analog of the Greek physisthesis distinction). In De Cive, Thomas Hobbes distinguished between unjustness (iniuria) and injustice (iniusticia), where the former refers to contracts within a specific social system and the latter to the social order as such. In Leviathan, however, justice does not exist outside of a specified system-justice is no longer a "natural" property, but a property instantiated by the social order. This is an early example of the contractualist theory of justice that was to become very important in the philosophical discussion.

In the nineteenth century, John Stuart Mill related justice to two aspects: a specified rule (maximizing the good for the greatest number of people) and a sentiment (the will to punish someone who breaks the rule). This combination tries to overcome the physis-thesis-distinction: Justice-related behavior involves both a "natural," sentimental aspect providing a motivational force for displaying justice (a sentimental basis that the principle of utility lacks) and a rational foundation that allows one to deal with a large variety of justice-relevant contexts including allocation (e.g., determining appropriate wages).

The twentieth century witnessed a reemergence of a normative understanding of justice as a distinct moral principle. In The Concept of Law, Hart (1961) sharply distinguished a moral and a legal understanding of justice and prioritized the former as an instrument for criticizing particular legal systems. More seminally still, in $A$ Theory of Justice, Rawls (1971) claimed that, given certain preconditions (among them, a "sense for justice" and a "veil of ignorance"), humans would agree in an ideal decision setting upon two principles of justice that include both a procedural and a distributive component. The procedural component is contained in the first principle of justice: "each person is to have an equal right to the most extensive basic liberty compatible with a similar liberty for others"; and the second part of the second principle: "Social and economic inequalities are to be arranged so that (b) offices and positions must be open to everyone under conditions of fair equality of opportunity." The distributive component is contained in the first part of the second principle (the "difference principle"): "Social and economic inequalities are to be arranged so that (a) they are to be of the greatest benefit to the leastadvantaged members of society." In a famous passage, Rawls describes justice as "the first virtue of social institutions" (1971, p. 3), in a sense of virtue that is not confined to individual agents.

The Theory of Justice focused the philosophical discussion on the distribution of goods. As a result, at present, "justice" is rarely used to capture all or large parts of morality, and most often refers to allocation problems. An important topic of debate 
is the relation between equality and justice. Prompted by Rawls' difference principle, some scholars require equality to be an independent component in a definition of justice. The basic intuition that connects justice with equality is that nobody should be worse off than others due to reasons for which he is not responsible. This is linked to the idea of "equality of fair opportunity," i.e., the socio-economic status into which one is born should have no impact on one's competitive prospects. Thus, according to Gerald Cohen, the goal of justice is "to eliminate involuntary disadvantage, (...) disadvantage for which the sufferer cannot be held responsible, since it does not appropriately reflect choices that he has made" (1989, p. 916).

Out of this connection of justice with a normative impetus to create equality of positive life chances for all humans, two strands of discussion emerged (Krebs 2000). The first - the "Equality of What?"-debate (Cohen 1993)_addresses the question of what has to be equalized in order to allow equality of opportunity. The answers given include "basic goods" (Rawls 1971), "resources" (Dworkin 1981), "welfare" (Roemer 1998), or "capability to function" (Sen 1992). This diversity reflects the difficulty that procedural and distributive aspects of justice actually interact. For instance, if the respective contributions of different agents are objects of justice considerations (e.g., performance-linked pay), then different starting positions (e.g., education) put people in different positions with respect to the process (e.g., the welleducated perform better). As a result, they earn more, which in turn allows their children to become better educated and helps to promote the idea that performancelinked pay is actually the "just" procedure in that specific context.

The other strand concerns the why of equality. The connection between equality and justice has been criticized on four grounds. Firstly, justice requires a minimal set of resources for all rather than equality with respect to resources (e.g., Frankfurt 1987). This line of critique is also skeptical about a purely relational understanding of justice, i.e., the idea that doing justice requires a comparison between agents. For example, if a person suffers from a disease, the justification for helping this person is not that there are healthy agents as well (this reason would disappear if everybody fell ill), but the fact that the disease itself is bad. Accordingly, justice does not rest on equality, but on the fact that there are intrinsically bad conditions. Secondly, equality may become too demanding in cases in which people are worse off due to their own fault. Nozick (1974) maintained that, given a procedural understanding of justice that complies with equality in opportunities, one must consider any distribution of goods that results from procedural justice as just. Changing this distribution cannot be justified on grounds of justice, but would require an independent rationale. Thirdly, the idea of equality does not fit the various cultures of justice. Walzer (1983) pointed out that there are very diverse principles of distribution of goods that apply to different spheres of social organization, e.g., free exchange, merits, and needs. He stressed that in arguing for distributive justice, one has to distinguish between types of goods (e.g., money, access to education, political functions, and medical treatment) and kinds of persons involved. Depending on the social sphere, the significance of these goods differs and, consequently, the distributions are valued differently. Finally, critics referred to the enormous contingency of human life conditions, which prevent equality from being 
realizable in practice. The problem is that a multitude of factors may contribute to a specific type of inequality and this creates the potential that many more aspects (genetic differences, various social aspects, etc.) have to be considered from the perspective of equality. It is thus unsurprising that empirical research like Jon Elster's "Local Justice Project," in which the allocation principles of numerous institutions in various countries has been investigated, reports a "bewildering surface variety of local justice phenomena [without] underlying principles that would bestow intelligibility on them all" (1992, vii). This means that the practical difficulties of realizing equality may be insoluble.

\section{Assessing Justice in Human Societies}

Researchers in animal cognition have rarely taken their cue from philosophical accounts of justice. Instead, they have sought to operationalize the notion of justice, following the lead of behavioral economists and social psychologists. In doing so, however, they have indeed relied on some of the distinctions we introduced earlier since these empirical studies have in turn been influenced by philosophical ideas. In order to help the reader understand the research on animal justice, we will now sketch the pertinent features of these empirical studies of justice in humans. This will also provide the background for our scheme for studying justice presented in the "A Scheme for Analyzing Justice" section.

First, several of the basic distinctions drawn in philosophy are employed by the empirical sciences as well. Examples are the respective roles of emotions and reason in considerations of justice and the distinction between distributive justice (focusing on the outcome, i.e., distribution or allocation of goods) and procedural justice (Skitka and Crosby 2003). There are indications that people tend to care more about procedural justice than about distributive justice (Liebig 2010). Inequalities in distributions resulting from violating principles of distributive justice are accepted more readily than equal distributions resulting from violations of procedural justice. One potential explanation is that procedural justice is more closely connected to the way one treats a person, i.e., to the respect for this person, than a resulting allocation of goods that often refers to anonymous rules. This is of interest, as the current research on justice in animals has an almost exclusive focus on distributive justice (see also Skitka 2012, this issue; Brosnan and de Waal 2012, this issue).

A second observation concerns the distinction between justice as an internal and an external principle. Empirical research demonstrates that behaviors which are evaluated as "unjust" from an external perspective are sometimes regarded as "just" from the perspective that a specific in-group holds (Hafner and Olson 2003). Even horrific crimes like terrorism have been committed in the name of justice. The critique of such acts must therefore include not just to the act itself, but the whole framework within which the act is presented as just. Similarly, one has to distinguish the issue of which rules are seen as just from the issue whether justice is invoked at all (Hafner and Olson 2003).

A third observation relates to various ways of making justice accessible to experimental tests. The most important of these are behavioral games (Camerer 
2003) used to establish the existence of, e.g., inequity aversion (Fehr and Schmidt 1999), paradigms that have been adapted by ethologists to make them accessible for animals (see the "Analyzing the Animal Justice Debate" section). The interesting point for us is this. Even among human subjects, variations both with respect to cultural context (Henrich et al. 2004) and to the games themselves result in diverging verdicts on situations and allocations as "just" or "unjust." For example, the range of options presented to players in ultimatum games influences whether a specific decision is considered as "just" or "unjust" (Jensen et al. 2007). Take the mini-ultimatum game, a reduced form of the ultimatum game in which proposers are given a choice between only two predefined offers which the responder can then accept or reject (Bolton and Zwick 1995). In one such study, Falk and colleagues (2003) showed that the evaluation of offers as "fair" was strongly dependent on the alternatives the proposer had when making his offer. The differential rejection of unfair outcomes across the games shown by the study suggests that people are sensitive neither solely to unfair distributions nor solely to unfair intent (Rabin 1993), but to a combination of both (Falk and Fischbacher 2006). Subjects take into account the range of options a social frame creates.

In the impunity game, a proposer obtains an endowment of money and decides how to split the money between herself and another individual, the responder. The responder has two options: either accept the offer and get his share-or reject the offer, and the proposer gets the whole money. Even in this game, a substantial ratio of responders reject money when the split seems unfair (Yamagishi et al. 2009, but see Bolton and Zwick 1995). This is taken as evidence that it is not necessarily inequity aversion that guides such choices, as rejecting the offer actually increases inequity. Even more surprising is the result obtained in a so-called private impunity game. In this game, the responder is advised that the proposer will not be informed about his or her decision, ruling out the possibility that the responder's decision provides the proposer with information-but again, 30-40\% of the players rejected unfair offers. Yamagishi et al. explained this as a by-product of emotion (typically anger or disgust). Such emotions prevent a shortsighted agent from accepting an unfair offer, an acceptance which might incur a long-term reputation loss when it becomes known. Nothing in the experiment, however, rules out that the responder does not want to take the responsibility for supporting unfair decisions. In this interpretation, an unwillingness to be responsible for tolerating unfairness would be the motivational force, as in the case of rejection the blame for unfairness is still on the proposer. These experiments show that it is not necessarily inequity with respect to allocations that is the object of evaluations of justice, but that the legitimacy of the distribution is also important. They also demonstrate the leeway one has in interpreting the results of behavioral experiments, provided that one does not have the opportunity to ask the subjects about their motives.

More generally, behavioral games yield three insights. Firstly, behavioral responses that are considered to be fair or unfair gain this label from the fact that the responder knows something about the intentions the proposers had when offering a specific allocation (e.g., whether an allocation was due to limited choice). Secondly, the moral motives that lead to specific behavioral reactions may be complex and not reducible to straightforward inequity aversion. Thirdly, deciding between the 
various possible explanations that these complications raise is hard in the case of subjects who cannot be consulted about their motives. ${ }^{3}$ These issues have to be taken into account when behavioral games are adapted for animal research (see the "Analyzing the Animal Justice Debate" section).

A fourth observation concerns research on the "sense of justice" in humans through neuroscientific methods (e.g., imaging, transcranial magnetic stimulation). This research looks for connections between player behavior in economic games and neural mechanisms that indicate involvement of basic emotional reactions. There are various problems with linking the diverse expressions of justice (and of other aspects of morality) in human life to specific sentiments (Christen 2010). It is equally problematic to characterize a particular behavior as having either a cognitive or an emotional source solely on account of which parts of the brain are most active during the behavior (Glock 2011, pp. 11-14).

A sophisticated sociological theory of justice has been presented by Liebig (2010). He distinguishes two types of justice: One refers to the exchange or distribution of goods, the other refers to procedures and social interactions when following (or violating) these procedures. With respect to the first type, he lists four well-known justice principles: equality (everybody gets the same), equity (reward according to contribution), desert (reward according to externally defined rights based on, e.g., gender, nationality, or past achievements), and need (reward according to personal requirements). The degree of legitimacy these principles can claim tends to depend on the form of social organization in which they are applied (Fiste 1993): In communities of common origin, the guiding principle is need; in hierarchical organizations, it is desert; in a peer group, equality; and in markets, equity. With respect to the second type, various principles play a role. One is neutrality, i.e., the requirement that no one be discriminated, e.g., on grounds of race or gender in a court of law. An important finding is that principles associated to procedures are less context-dependent than those related to distributions and that there is less disagreement between members of different cultures with respect to the validity of these principles. In the following section, we partly rely on the distinctions drawn by Liebig.

\section{A Scheme for Analyzing Justice}

Based on the philosophical and empirical considerations above, we will now outline a basic scheme for understanding justice. We treat justice as a concept that includes the perspectives on allocations and distributions, on procedures when creating these distributions, and on the interactions of the agents. Two distinctions are relevant for us.

\footnotetext{
3 Here, one has to take into account that even when subjects can be consulted about their motives, people are often unable to accurately report their motivations. This is a problem in self-report studies, indicating that one should be more reliant on behavioral outcomes than on self-report in both humans and other species (Brosnan et al. 2009).
} 
The first refers to the elements that interact in a situation which raises questions of justice, and which can hence become an object of justice considerations. Those elements are (see Fig. 1):

- Agents that have certain psychological competences and needs. As mentioned in footnote 1, we understand the term "agent" in a broad sense which allows for the possibility that some non-human animals are agents.

- Resources that are regarded as either intrinsically good (e.g., food) or as prerequisite for generating an intrinsic good. Goods can in turn become resources for creating further goods, i.e., something is a resource relative to a process in which the resource serves as input. Resources and agents are interrelated by relationships of, e.g., need.

- Social organizations of different types that frame the interactions between agents and resources. This involves, e.g., hierarchies and division of labor.

- Procedures that prescribe how agents and resources should interact when creating a good-i.e., the normative frame of agent-agent and agent-resource interactions within a process. This framework may have an explicit (e.g., laws) or implicit form (e.g., traditions). It may involve access rights, guidelines, etc.

- Efforts that relate agents with agents as well as agents with resources when creating a good, i.e., the actual behaviors, which may deviate from the behavior prescribed by the procedures.

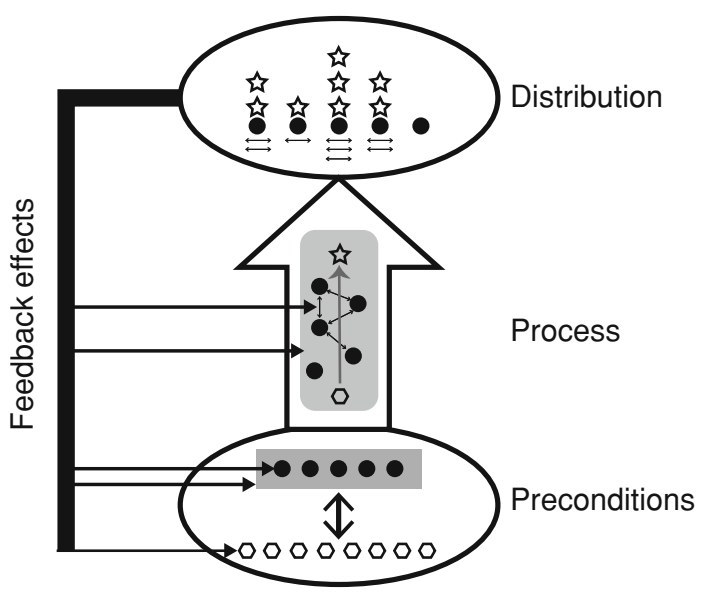

Fig. 1 The interrelations among the elements relevant for any concept of justice concerning the distribution of goods: The preconditions include agents (black circles) that are embedded in a social organization (gray rectangle) and that have access to resources (hexagons). These agents form a network by interacting in a process guided by procedures (gray rectangle with round corners) through actual efforts (edges in the network, here represented by arrows), transforming resources into goods (stars). The result of such a process is a distribution of these goods among the agents and of the efforts involved in creating the goods. This distribution (shown is a distribution realizing the normative principle of equitythe rewards correspond to the efforts) has feedback effects on all other elements (see the example in the text for further illustration) 
- Goods that result from those processes. Note that processes that lead to the goods and processes that lead to the distribution of these goods are conceptually distinct, yet can de facto be entangled.

- Distributions, the relation between goods, efforts, and agents. Distributions depend on which goods an agent possesses, has access to, etc. (this depends on the kind of good), and what the agent's contribution was in generating this good (this depends on procedures and efforts).

Figure 1 illustrates the interaction of these elements. Consider the following example. Five lumberjacks (agents) hired in a piecework agreement (social context) go to the woods to cut down trees (resources). The most experienced lumberjack gives the orders for when to fell each tree such that no one gets hurt (procedure). There are various steps required to fell a tree properly-placing a saw kerf and a dropping cut, hammering in a chock, removing branches, cutting the trunk into smaller pieces, etc. (efforts). The lumberjacks have to interact properly in order to produce the proper logs (goods). At the same time, their contributions vary dramatically - in particular, one lumberjack does not participate in felling the trees because he has had a bad day. At the end of the day, the lumberjacks have contributed differently to the total amount of logs produced and are paid in logs according to their contribution (distributions). Based on the result of this day's work, various feedback effects may influence collaboration in the future. For example, the best trees may already have been felled (changing the resource basis), the lumberjacks may think that it is unfair that a colleague who has had a bad day does not get equal pay (changing the social context), or they may change their method to optimize felling based on previous experiences (changing the procedure).

When justice in animals is the object of investigation, the possibility to identify and analyze these elements differs: Agents (as understood here), resources (in particular, food), social organizations (e.g., hierarchies), and efforts (i.e., the actual behaviors) are least problematic in that respect. The notion of a good requires the involvement of some process to create this good (collective hunting is an example). And there are difficulties in distinguishing resources from goods in certain simple processes. For instance, should just picking and instantaneously eating berries be considered as a process that transforms a resource into a good? The problem is that, unlike humans, animals in the wild engage almost exclusively in such simple processes. Next, the notion of distributions requires both a cognitive ability to quantify and keep track of goods (who got what?) and some durability of the good itself (e.g., food storage). The former is difficult, though not impossible to identify in animals (for primates see Tomasello and Call 1997, Ch. 5), and the latter is relatively rare among cognitively advanced mammals. Finally, procedures are the most problematic element, namely the identification of some kind of "tradition" or "norm" in animal societies with respect to justice. A procedure is more than a mere "automatic" behavioral reaction with respect to some specific situation (e.g., a conspecific gets more food than the other animal, triggering an emotional reaction). It is a rule that guides and rationalizes agents' behavior (see next section). Procedures should also have some degree of generalizability with respect to the agents and resources involved (e.g., be valid for most of the group members and for 
different kinds of food). As procedures are essential to procedural justice (notably the question of whether agents are contributing to a good in a way expected from them), the difficulty in identifying procedures may explain why procedural justice has rarely, if ever, been investigated in animals.

These elements are arranged as described in Fig. 1. Within this schema, four basic levels can be distinguished: Firstly, preconditions of distributive justice, i.e., agents, resources, and social organization; secondly, the process that generates a good based on the preconditions, namely through procedures and efforts; thirdly, the distribution of goods that results from applying the process; and fourthly, the feedback of the distribution both on the process and the precondition levels. Feedback can affect all other elements. First, generated goods can become resources for further processes. Next, the fact that certain goods have been allocated to a certain agent can have immediate effects on her psychological competences (e.g., experiences, confidence) and change her position within the social organization. Furthermore, it may change the procedures (i.e., if the distributed goods consist of access rights) and the actual efforts of agents. Figure 1 thus reveals that the different facets of justice outlined by Liebig (2010)—procedural, organizational, distributive-are closely connected.

Our second relevant distinction concerns the criteria on which judgments about justice are based. Such criteria determine how subjects evaluate the aforementioned elements from a normative point of view. Given the perspectives described by Liebig (2010), the focus of evaluation can be on the distributions (distributive justice) or on the (mis-)fits between procedures and actual efforts (procedural justice). This evaluation does not require that the evaluating subject possesses elaborate theories about justice. The subject must only show its potential awareness of the parameters involved in normative evaluations. Those parameters are:

- The subject of justice concerns: Who does an agent consider to be the subject of violations of justice? The focus can be only self-regarding (e.g., the agent only cares about her own reward), other-regarding (e.g., the agent cares when another agent is treated unfairly), in-group (e.g., a group reserves justice considerations for its own members), and out-group (a group considers justice with respect to outsiders).

- The object of justice concerns: This refers to the accessibility of the elements of justice to the agents. Agents must possess certain cognitive capabilities in order to realize that a norm of justice is violated. The distributive focus is the least demanding, whereas a procedural focus requires sophisticated competences, e.g., for accepting abstract values.

- The variability of justice concerns: This refers to the number of criteria used in a judgment about justice. One may have only one criterion that is applied to all social situations (e.g., everybody gets the same) or one may have many criteria as well as conditions that determine which criteria are applied in which situations (e.g., along the typology proposed by Fiste 1993). Again, the more criteria are employed, the higher are the requirements with respect to the cognitive capabilities of the agents. 
- Expression of justice concerns: This refers to the way a concern for justice is manifested by an agent toward other agents. The behavioral manifestation may be very limited, e.g., allowing only showing displeasure in the face of inequity. At the other end of the spectrum would be language-based reasoning and argumentation for specific justice concerns.

Animals are obviously unable to make use of the whole spectrum of possibilities these four parameters of judgments about justice offer. And we have already noted that there are limits to the degree to which the elements of our scheme are implemented in animal societies. Therefore, the question raised by our schema for justice is: to what extent are animals able to fulfill its elements and how much of the spectrum the parameters of justice concerns offer can they satisfy ? $^{4}$

\section{Justice and Mental Capacities}

Before tackling that question with a view to specific empirical research conducted over the last few years, some fundamental philosophical issues need to be mentioned. These concern the conceptual connections between a sense of justice, on the one hand, and cognitive and conative mental capacities, on the other.

Let us first note that some contributions to the debate about justice in animals employ "justice" in the older and more general sense of referring to morality as such (notably Bekoff and Pierce 2009; see also Pierce and Bekoff 2012, previous issue). Quite independently of this usage, "fairness" rather than "justice" seems to be the term most often used in animal research. This may be due to a largely implicit tendency to regard justice as a more demanding and diffuse phenomenon compared to less demanding and more tractable phenomena like fairness or inequity. Note that there are different ways in which justice could and has been contrasted with fairness. Firstly, there is the distinction between more or less complex phenomena: Justice might be held to be the more inclusive phenomenon (e.g., involving all the features outlined in our scheme), while fairness only encompasses a selection. Then, there is the distinction between justice as an objective social phenomenon and fairness as a feeling or reaction on the part of agents. And finally, one can distinguish two such reactions - a sense of justice which is more reflective, cognitive, and cultural, and a sense of fairness which is more spontaneous, affective, and natural. Thus, some psychologists distinguish between a "sense of fairness," which is a spontaneous sentimental reaction and a "sense of justice," which is a more elaborate and well-considered response that results from moral expertise (Narvaez and Lapsley 2005). This may help to keep apart behavioral reactions that emerge rather spontaneously and may often be considered as "unfair/-just" from those emerging from a "sense of justice." The latter is supposed to be more reliable in producing the "ethically right" answer and it is linked to a complex social frame in which human subjects are trained and cultivated. In a similar vein, Rawls

\footnotetext{
${ }^{4}$ Note that variants of this question arise independently of accepting our scheme as whole. For, at least some of the elements and parameters we identify undoubtedly play a role both in standard concepts of justice and in justice-related phenomena.
} 
described the sense of justice as a motivational force that develops after just institutions have been introduced (see also Scarano 1998). Note that these "senses" are not equivalent to the ability to actually behave in a just manner. One may react to something as unfair or unjust without being able to do something about it, e.g., because of weakness of will. These senses are psychological dispositions or competences the agents have-the former is more affective and supposed to have more ancient phylogenetic roots, while the latter is more reflective and primarily rooted in the cultural history of a group or society.

In any event, it is generally recognized that both (a sense of) justice and (a sense of) fairness require more than pro-social behavior of the kind on display, e.g., in insect societies. The pro-social behavior must also be intelligent, i.e., flexible and plastic (see Bekoff and Pierce 2009, pp. 12-13). There is an underlying rationale for this requirement. As in the case of genuine altruism, pro-social behavior acquires the moral significance attached to justice only if it is intentional in the sense of being explicable by reference to the agent's goals or reasons, to what she believes, desires, intends, etc. Die-hard differentialists notwithstanding, there are no grounds for denying that non-linguistic animals can have beliefs and desires; and it is arguable that they are capable of acting not only in pursuit of goals, but also for reasons, i.e., in the light of how things are or appear to be.

The moot question is what types of beliefs and desires can be attributed in the absence of language. Here, the specter of indeterminacy raises its ugly head. Barring the option of asking the subject about its reasons or motives, it may be impossible to distinguish reasons of any but the most fundamental type. There may be no way in principle for determining whether a pro-social action was performed, e.g., for the reason that the beneficiary is in need and deserving of help, or for the reason that the beneficiary will (feel obliged to) reciprocate, or for no genuine reason at all but, e.g., out of a diffuse empathetic tendency. And without ways of deciding between such alternatives, talk of reasons may lose its grip altogether; at any rate, it is not operational in the way required for empirical research.

Another problem concerns the space for deliberation or reasoning. It is clear enough that intelligent animals chose between different options. But can they be said to make decisions based on considering and weighing their options? Finally, there is the role of the will for moral agency and moral powers in general and for justice in particular. We normally accord praise or blame to humans on the assumption that they have deliberately chosen a particular course of action or could at least have refrained from it. This does not presuppose freedom of will in the spurious sense of an unconditioned, uncaused volition. But it may presuppose that subjects be capable of manifesting a moment of decision and/or that their actions are under their control in accordance with their reasons. And it is contentious whether animals possess these powers (for more on these issues see Glock 2009).

Returning to the types of beliefs and desires that animals can be credited with, the crucial question is precisely which of those required for a sense of justice or fairness they include. One prominent issue here, as in the case of altruism, is whether animals are capable of entertaining beliefs, desires, and intentions about the beliefs, desires, and intentions of others. As mentioned in the "Assessing Justice in Human Societies" section, when human participants in behavioral games react to an action 
by other players as fair or unfair, this is often based on beliefs about the intentions of these other players. Furthermore, the capacity for beliefs about the beliefs and desires of others is a precondition for most, if not all, beliefs about what these others deserve in a certain situation. Such beliefs often presuppose beliefs about the behavior of others being worthy of praise or blame. And the latter beliefs in turn standardly presuppose beliefs about the motives or intentions behind the behavior. Even leaving the aforementioned issue of deliberate choice aside, we accord praise or blame differently to intentional and unintentional behavior. And even when we blame a subject on grounds of culpable negligence rather than malign intentions, we rely on beliefs about what the subject knows or could have known. Finally, a belief to the effect that a subject deserves a certain treatment by way of reward or punishment cannot be independent of beliefs about what that subject desires or resents.

Accordingly, there are important dimensions of justice considerations that are foreclosed to subjects lacking the capacity for entertaining beliefs, desires, and intentions about the beliefs, desires, and intentions of others. This capacity is often referred to as possession of a "theory of mind." Yet, no ability for genuine theory construction is required even in the case of humans, which is why the increasingly popular label "mind reading" is to be preferred (see Bermúdez 2009; Hurley and Nudds 2006, 429n). Nevertheless, whether even the most intelligent animals are "mind readers" rather than mere "behavior readers" is a contested issue within cognitive ethology (cp. Tomasello and Call 2006; Povinelli and Vonk 2006). In our view, this contrast may be overdone. Intentions, for instance, are often manifest in behavior, with the consequence that reading behavior often is reading intentions. But it is nonetheless a philosophically and empirically vexed issue whether animals can entertain beliefs, e.g., about the intentions and desires (subjectively felt needs) of others.

Even assuming that precondition to be fulfilled, further difficulties arise when it comes to the moral, non-egoistic dimension of justice considerations implied by the notion of desert. How is one to decide between animal 1 believing that animal 2 deserves a certain treatment rather than believing that meeting out the treatment will have positive consequences for animal 1 ?

These challenges are connected to the theme of rules or norms. Rules are essential to what we have called procedures. And even among assimilationists, many recognize that they are indispensable to morality in general and justice in particular (see Bekoff and Pierce 2009, pp. 115-116, 121). But it is imperative to get clear about what is involved in rules and rule-following. In what follows, we adopt a perspective on normative phenomena that ultimately derives from Wittgenstein and has been hotly debated in contemporary philosophy in the wake of Kripke (1982) and Brandom (e.g., 2000). ${ }^{5}$ First and foremost, rules are standards against which

\footnotetext{
5 Our specific version is particularly indebted to von Wright (1963), Hart (1961), Baker and Hacker (1984), and Searle (1997). Although it has a different aim (namely to elucidate the conceptual connections between normative phenomena, language, and thought rather than to explain the emergence and stability of social rules in human societies), the Wittgensteinian conception is congenial in many respects to the influential account of social norms developed by Bicchieri (e.g., 2006). It distinguishes between rules and rule-guided behavior, while insisting that rules must at some level be embodied in
} 
something (notably behavior) can be assessed as correct or incorrect. They have a world-to-mind direction of fit. By contrast to an expectation, if a rule is violated, it is the world (behavior) that needs to be brought in line rather than the rule. If planets turn out to follow paths other than elliptical ones, it is Kepler's Laws-a theoretical belief - rather than the movement of the planets which need revision. By contrast, if I drive on the left-hand side, it is my driving rather than the Traffic Code which is at fault.

Secondly, rules provide reasons for action. Although rule-following presupposes regularity in behavior, there is a difference between following a rule and merely acting in accordance with a rule. If an agent follows a rule in $\Phi$ ing, the rule must be

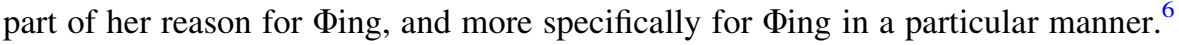
This once again draws in its wake a requirement that the behavior be intentional. If an animal merely has a disposition, e.g., to share food with conspecifics without intending to do so, it will not be following a rule. And this holds even if the responses that manifest the disposition are "correct" in the sense of being adaptive. Thirdly, rules are inherently general, by contrast to normatively loaded expectations about a specific situation such as the expectations behind commands. Although rules are commonly restricted to certain subjects, they govern an unlimited multiplicity of occasions.

These three points pose challenges to the idea that animals can follow rules. These arise from the fact that animals are incapable not only of justifying their behavior by reference to rules, but also of recognizing the formulations of the rules they are purported to follow. Ironically, however, these challenges may be weakened rather than strengthened by the fact that the rules involved in justice must satisfy an additional condition, namely being social, in force within a community or group. In a community $\mathrm{C}$, a behavioral regularity $\mathrm{R}$ is a shared rule if and only if it satisfies three additional requirements, to wit: fourthly, it is rare for members of $\mathrm{C}$ to deviate from $\mathrm{R}$; fifthly, if members of $\mathrm{C}$ deviate from $\mathrm{R}$, they are subject to sanctions; sixthly, these sanctions are generally accepted by members of $\mathrm{C}$. The communal interactions of requirements four and five can indicate the world-to-mind fit (requirement 1) and the difference between a rule and a regularity (requirement 2 ), which might otherwise be difficult to ascertain in a non-linguistic creature $S$. The Фing of $\mathrm{S}$ can be norm-sensitive-correct or incorrect-in the sense of being approved or disapproved by other members of the community. S's intention of following the rule to $\Phi$ can be manifested in S's reacting to the approval or disapproval in combination with S's in turn approving or disapproving Фing by

\footnotetext{
Footnote 5 continued

behavior, though this need not consist in compliance with the rule. It also denies that only behavior accompanied by conscious deliberation or consultation of rules can count as rule-guided. By contrast to the Chomskian conception of syntactic rules, however, it insists that subjects must at least be capable of recognizing suitable formulations of the rules they are following, since otherwise the all-important difference between following a rule and merely acting in accordance with a rule is lost (see Baker and Hacker 1984: Chs. 8-9; Searle 1997 and Glock 2012a).

6 As the antecedent makes clear, the claim that rules provide reasons for actions does not imply that subjects have reasons to follow any given rule independently of their intentions, e.g., even when they repudiate that rule.
} 
these other members. All that is required is the possibility to distinguish mere surprise from disapproval among the members of this non-linguistic community.

Accordingly, there are no compelling grounds for denying that animals can follow communal rules in general (see Glock 2010, pp. 91-96). As regards justice in particular, at least one difficulty remains nonetheless. Because of requirement 2, animals can follow a rule only if they have some kind of understanding of that rule. Causes of our behavior that we are completely and irredeemably ignorant of cannot be reasons for us and hence cannot be rules in the sense employed here (see fn. 5). The fundamental conceptual and methodological hurdle for animals this poses is the following. The kinds of rules implicated in justice are complex, involving the aforementioned mind-reading and moral dimensions, especially through the notion of desert. It is the content of a particular type of rule that may demand too much from animals, not normativity per se.

Many assimilationists dismiss philosophical qualms about animal minds in general and animal justice in particular by a reference to principles of biological continuity (e.g., Bekoff and Pierce 2009, xi, 113, 137). Since we are no less a product of evolution than other primates, the reasoning goes, there cannot be any substantial differences between them and us. However, continuity along individual lineages of evolutionary development has no implications for the mental capacities of the animals around us. Saltationism notwithstanding, it is probable that our closest evolutionary ancestors shared many of our other mental capacities. Yet, these ancestors are extinct; and there is no guarantee that the biologically closest extant species-our nearest relatives - are mentally close to us. If all vertebrates except homo sapiens had been vanquished by a wayward meteorite, it would be absurd to conclude that starfish and sea cucumbers must be mentally close to us and hence share our sense of fairness or justice.

\section{Analyzing the Animal Justice Debate}

We now return to our question: To what extent does animal behavior actually display aspects of the complex phenomena and cultures of justice we encounter in humans, or simpler variants of these elements (see also Brosnan 2011a)? More specifically, keeping in mind the conceptual and methodological issues broached in the "Justice and Mental Capacities" section, we will explore how animal behavior recorded and investigated in recent ethological research can be related to the distinctions (elements of justice, normative criteria in justice concerns) drawn in the "A Scheme for Analyzing Justice" section. While we cannot speculate on the evolutionary roots of the sense of justice here, our exercise should also help to prepare the ground for deciding which simpler variants may have been precursors of justice in humans.

Before we start, we review and comment on the major types of experiments ${ }^{7}$ done so far and provide some examples. The research we report was done with

\footnotetext{
7 We disregard observational studies of animals in the wild and in captivity, even though they are still a major source of much research on pro-social behavior. We also disregard the interesting research on fairness in social play among mammals (see Bekoff and Pierce 2009, Ch. 5).
} 
primates, although there are few studies on non-primates (e.g., dogs; Range et al. 2009). Most of the primate experiments were follow-up studies after Brosnan and de Waal (2003) and Brosnan et al. (2005) claimed to have found a negative reaction to inequity (defined as unequal outcomes). Those studies are discussed in more detail in other contributions to the special issues of Social Justice Research (see Price and Brosnan 2012, previous issue; Range et al. 2012, previous issue; Horowitz 2012, previous issue; Bräuer and Hanus 2012, this issue; Yamamoto and Takimoto 2012, this issue). Therefore, we only outline the experimental paradigms and provide references for further details. We classify these studies into three groups.

\section{Inequity Experiments-Animal-Human Without Task}

This setting is characterized by a human treating two animals differently with respect to the distribution of goods, such that the subjects witness "inequality." The inequality lies in receiving food that is more or less preferred, and the rewards are not based on differences in the prior behavior. The aim of the experiments is to find out whether the animal reacts to this observed difference. The behavioral reactions employed to measure such a sensibility include rejection of the good and latencies in taking the good. There is no animal-animal interaction beside mutual observation and the possibility to display, e.g., begging behavior, although in some settings, the animals are physically close allowing, e.g., one animal to take the food the other animal has rejected. The human-animal interaction consists in handing over food; the animal only needs to grasp food, which is considered an "effortless" condition. Various controls are included: the absence of a witness, the visibility of food, the type of food, and the hierarchical relations of the animals in the group. An example of such a study is Bräuer et al. (2009). They used a $2 \times 2$ factor design (the presence or absence of the competitor in a second cage, handing over low- or high-value food) and tested for various control conditions (the presence or absence of food, different places of the animals in the social hierarchy, the presence of a frustration effect, different species_orangutans, gorillas, bonobos, chimpanzees). They were not able to replicate the "inequity aversion" behavior found by Brosnan et al. (2005). The latter found that chimpanzees showed increased levels of rejection for less-preferred food when competitors received better food than themselves for completing a task. By contrast, the apes of Bräuer et al. ignored fewer food pieces and stayed longer at the testing station when a conspecific got favored food. Moreover, the subject begged more when the competitor was present than when she was absent; chimpanzees, in particular, also begged more when the conspecific got favored food. These results are the opposite to those of Brosnan et al. (2005), as subjects ignored food less rather than more when the competitor received food of higher quality than they themselves did. Bräuer et al. concluded that if food refusals are the key to inferring inequity aversion, then the apes in their study were not inequity averse.

\section{Inequity Experiments-Animal-Human with Task}

This setting adds to the previous one, namely a task the animal has to fulfill (e.g., exchanging a token) in order to get food. It includes what we call a procedural 
element (effort) and tests whether the animal is actually sensible to differences in effort. These tasks are embedded in human-animal interactions and not in animalanimal interactions.

The first study using this approach was published by Brosnan and de Waal (2003). Two animals exchanged a token for food (either preferred-grape; or less preferred-cucumber); the behavior of animal 2 is the observable. In the "equality condition," both animals obtain cucumbers for their tokens. Compared to this condition, animal 2 exchanged a token for a cucumber less often when animal 1 got grapes for the token (inequality condition), got the grape for free (effort control), or before the exchange grapes were given for free to animal 2 in the absence of animal 1 (food control). The fraction of non-exchanges increased over time for the inequality condition and the effort control, but decreased for the food control. Taken together, these results were interpreted as evincing inequity aversion: Animals refused to participate in an exchange task if a conspecific got more for performing the same task or even for not performing a task at all.

This study and a follow-up study with chimpanzees (Brosnan et al. 2005) were criticized by various scholars. Thus, it has been claimed that the mere presence of better food caused the rejection of the less-preferred food (Wynne 2004; Dubreuil et al. 2006) due to frustration effects (Silberberg et al. 2009), that the behavior cannot be called inequity aversion as rejecting food actually increases inequity (Henrich 2004), and that there was no similar reaction in situations that should equally trigger such a response (Bräuer et al. 2006, 2009; Jensen et al. 2006, 2007; for a summary, see Bräuer and Hanus 2012, this issue). In follow-up experiments using the same experimental paradigm (e.g., van Wolkentet et al. 2007; Brosnan et al. 2010), some of the criticisms were addressed. Firstly, several controls show that while the subjects respond aversely when a partner receives better food, they do not respond aversely when better food is simply available to the partner. This may indeed rule out the possibility of a frustration effect, but it is compatible with a social emotion like envy (see below).

Secondly, it seems that the inequity response is a function of the effort. When the effort is substantial enough, the animals are more inclined to accept even a lower (i.e., inequitable) reward. However, the overview in Brosnan et al. (2010) reveals a rather complex pattern of inequity aversion in chimpanzees. The presence of a task seems to be important, though not in all studies (Bräuer et al. 2009); males show more inequity aversion (i.e., they refused more often to complete the interaction with the experimenter when the partner received a better outcome), and there are indications of "prosocial" rejections by the animal that benefits: Chimpanzees were more likely to refuse a high-value grape when the other chimpanzee got a lower value carrot than when the other chimpanzee also received a grape. It would appear that there are substantial differences between chimpanzee populations with respect to inequity aversion, yet given the indeterminacy in interpreting the motives of nonlinguistic subjects, the reasons are difficult to fathom (see Price and Brosnan 2012, previous issue).

It is important to note one general limitation of this experimental setup. It assumes that animal 2 compares the relation between its own effort and its own good to the relation between the effort of animal 1 and the good it receives. But it 
cannot capture differences between kinds of processes that can lead to such differences. Contrast a lottery in which person 2 exchanges money for a lottery ticket that involves either a high or a low reward. Seeing person 1 getting a higher reward for the same investment would not be considered a violation of justice in a human context by contrast to a scenario in which person 2 has to pay a higher price for the lottery ticket. The feeling of disappointment in person 2 who got a low reward for his ticket is rather a frustration effect, even though it may induce person 2 to refuse the lottery reward.

\section{Inequity Experiments-Animal-Animal with Task}

These experiments eliminate the animal-human interaction and replace it with an animal-animal interaction, i.e., animal 1 has the option to offer different distributions of goods (usually food) to animal 2 (an act that involves a task), and animal 2 has the option of reacting to this offer. These experiments seek to adapt behavioral games played with humans (e.g., impunity, dictator, or ultimatum game) to animals. The inequality usually consists of quantitative differences (i.e., the same food yet different amounts). The effort at issue depends on the experimental paradigm. Either only one animal has to perform a task or both have to; in the latter case, the two tasks are interrelated so as to constitute collaboration. The behavior of both animal 1 and 2 can be objects of the investigation. In animal 1, one can observe whether its choices benefits animal 2 as well, whereas in animal 2, one can observe its reaction (rejecting food, begging behavior, performing a specific task required for obtaining the food). In some experiments, one can vary the tasks involved and thus make effort an observable as well. For instance, one can compare a situation in which the difference in efforts of the two animals is small to a situation in which one animal contributes much more in the collaboration than the other animal. But one has to keep in mind that combining differences in effort with differences in evaluation of outcome is tricky. Motivation research in humans shows that the involvement of effort increases the probability that an outcome that is normally less valued is valued more. This effect also seems to play a role in animal experiments involving the valuation of efforts and outcomes (Neiworth et al. 2009).

An example of a study focusing on animal 1 is Fletcher (2008). A variant of the dictator game is played by capuchin monkeys, i.e., a chooser decides between two distributions of goods for him and a second receiver. Capuchin subjects were given two choices that had the same payoff for the chooser (one piece of food), but were either equitable (animal 2 receives one piece) or inequitable (animal 2 receives three pieces). The results showed a tendency of inequity aversion: The choosers more often selected an equal distribution of food. An example of a study focusing on both animals (chimpanzees) is Jensen et al. (2007). They used a mini-ultimatum game in which the proposer chooses between two preset offers which the responder can then accept or reject. The results showed that (i) responders tended to accept any offer; in particular, they did not reject unfair offers when the proposer had the option of making a fair offer; (ii) proposers did not appear to take outcomes affecting the responder into account. Interestingly, even when the proposer offered no food at all 
to the respondent, the latter allowed the proposer to get the full share in $56 \%$ of the cases (see also Smith and Silberberg 2010).

Finally, Takimoto and Fujita (2011) conducted an experiment in which the tasks varied in order to test the sensitivity of capuchin monkeys to the labor contributed by conspecifics. An operator monkey pulled the drawer of one of two food containers placed between two monkeys, each containing a food for the operator and another for a recipient monkey. The recipient received either high- or low-value food depending on the operator's choice, whereas the operator obtained the same food regardless. In the unequal labor condition, the operator had to perform two actions to obtain food (pull the handle of the board to which the containers were glued; release food by pulling the drawer of one of the containers), whereas in the equal labor condition, the first action was performed by the recipient. The tasks were sequenced as follows: first, an unequal labor condition; second, an equal labor condition; and third, again an unequal labor condition. This allowed subjects to distinguish the third condition-i.e., the second with unequal labor-from the first. Potential "unfairness" (the recipient gets food without working) was highlighted in that third condition (the third overall) as the recipient had cooperated beforehand in the second, i.e., equal, condition. However, one aspect of human justice is not fulfilled in such a setting: The unequal labor condition did not allow any choice to refuse collaboration by the recipient. We therefore would not say that the responder has acted "unjustly", as the context did not allow justice. The result showed two things: Firstly, only in the equal labor condition did operators chose the high-value food container for recipients more often than when the recipient was absent. Secondly, the receiver showed significantly less begging behavior in the second unequal labor condition. This suggests that capuchin monkeys are sensitive to the labor of others. For one thing, the operator gave more food to a partner who had helped them to complete a task. For another, the recipient showed less frustration in the final condition, i.e., the second condition with unequal labor distribution, in which the contrast between cooperation and not cooperating was enhanced compared to the first unequal labor condition, perhaps because the recipient was able to cooperate in the trial before. There was, however, no significant behavior that could be related to inequity aversion, i.e., in the second unequal labor condition; the operator did not "punish" the non-cooperator by giving him the low-value food more frequently.

We will now further evaluate this research by applying our scheme of the "A Scheme for Analyzing Justice" section. We start with the elements of justice and their potential implementation in animal societies:

- Agents: The agents under consideration (i.e., primates) possess basic cognitive and conative abilities: they recognize and evaluate the behavior of conspecifics and value different food more or less. As outlined in the "Justice and Mental Capacities" section, there are no grounds for denying that non-linguistic animals can have beliefs and desires; and it is arguable that they are capable of acting for reasons (see fn. 2 and the "Justice and Mental Capacities" section above).

- Resources: Almost all studies involve food as the main resource, even though other resources (e.g., access to mating partners, territory) could also be 
investigated. The reason is that food experiments are relatively simple to set up: Animals like to eat almost irrespective of circumstances, the behaviors associated with food (grasping, finding, problem solving, etc.) are relatively simple, and inequality can easily be measured.

- Social organizations: Due to the hierarchical nature of most primate societies and the often extreme imbalances in power, distributive justice will almost certainly not amount to equality (Brosnan 2006). Equity in a group of animals may boil down to a balance in which dominants get the lion's share, while making membership of the group attractive enough so that subordinates do not abandon the group. It is therefore remarkable that experiments have in many cases failed to detect a distribution pattern that benefits dominant individuals (e.g., Takimoto et al. 2010; but see Brosnan et al. 2010, and Bräuer et al. 2009). This may indicate that the experimental settings are somehow artificial by comparison to the interaction patterns of the animals in the wild, which may weaken their significance and explanatory power.

- Procedures: We have already commented on the complex preconditions of rulefollowing in general and of following rules of justice in particular. But there is also a factual limitation to animal justice. There appears little evidence from either the wild or captivity that primate communities, at least, enforce any kind of distributive rules on a third-party basis. The closest one seems to get is thirdparty mediation in communal fights (e.g., de Waal 1996), which is an aspect of organizational interaction justice in the scheme we adapted from Liebig. Siblicide and infanticide are other examples of "anti-social" behavior that causes distress for individuals, but which is not sanctioned by third-parties within primate communities. The relative absence of the social enforcement of "moral rules" in primates reflects a more general fact. The interaction among those primates that are cognitively closest to us is significantly less cooperative than it is among humans (Tomasello 2009), perhaps because they are not cooperative breeders (Burkart and van Schaik 2010). We should also note that even if there is an "internal" sense of justice among animals, i.e., established patterns of distribution, there is no obvious external perspective, no questioning of the principles of justice in force in a particular group.

- Efforts: As regard efforts, they are basic, yet can involve both animal-human (token exchange) and animal-animal interactions (pulling ropes). The social interactions that the experiments permit are, however, highly restricted. In many experiments, the only interaction among conspecifics is watching the behavior of each other and begging behavior. In some experiments, one animal can take food away from the other animal if the latter refuses eating it. There are indications that animals show sensitivity to efforts. But as indicated above, this sensitivity seems to not be a very stable phenomenon, i.e., it seems to vary between groups of the same species, depend on gender and the type of effort, etc.

- Goods: As the resource used is food, the function of transforming it into a good is simple: the validation of the food as more or less preferred on account of either quality or quantity. This is a rather simple kind of a good, in particular, as food storage or any kind of food processing seems to be very rare (an example is 
given Marriott and Salzen 1979), possibly because there is no opportunity for storage (Brosnan 2011b).

- Distribution of goods: There are two types of inequality investigated in the experiments: inequality with respect to food validation and inequality with respect to effort involved. But whether the animals are sensitive to inequalities in distribution of goods and/or efforts necessary to obtain food is not so clear given the data available so far. This sensitivity seems to depend on various aspects (gender, species, and design of the experiment; see Price and Brosnan 2012, previous issue).

With respect to the dimensions of justice concerns, the experiments once more demonstrate only very basic variants:

\section{Subject of Justice Concerns}

In almost all studies, the subject of justice concerns is the agent himself, in particular with respect to disadvantages. This means that animals have a sensibility to situations in which they themselves are disadvantaged - in particular with respect to food distributions, but less with respect to inequalities in effort. In exchange experiments, there is very little indication of inequity aversion on the side of the proposer (Brosnan et al. 2010).

Assimilationists interpret these results as showing that of two types of inequity aversion, only one is present, namely to others receiving more, while there is little to no aversion to receiving for oneself more than others. But the question arises whether the first type actually instantiates a sense of fairness at all rather than a sense of greed or, more appositely, envy. Assimilationists have responded to this challenge by maintaining that both are counterparts to justice: You only feel envious because you feel shortchanged (Bekoff and Pierce 2009, pp. 127-128). However, in the absence of the second type of inequity aversion, feeling shortchanged does not evince a sense of fairness. Assimilationists speak of a sense of "indignation" here (Brosnan and de Waal 2003). But how precisely is indignation to be distinguished from envy in the absence of language or facial expressions of a human kind? ${ }^{8}$ And without something like indignation, exclusively egoistic inequity aversion does not amount to righteousness. It does not even amount to an exclusively self-serving feeling that one has not received one's due share. For, even such a one-sided "selfrighteous" feeling presupposes that the subject can recognize that the rules of distribution apply equally to others, and that it could be these others who have not received their fair share. In the absence of indignation, equity aversion is neither righteous nor self-righteous, it is simply not part of the realm of righteousness. By the same token, inequity aversion without an other-regarding sense of equity is not a special kind of "primate" distributive justice as some would have it; it is simply Hamlet without the Prince of Denmark.

\footnotetext{
${ }_{8}$ As Brosnan remarks (see Introduction to this special issue), it is remarkable that even experiments with humans rarely include actual controls for envy.
} 


\section{Objects of Justice Concerns}

In the experiments done so far, only elements that are directly accessible to the animal have been investigated, namely food inequality and effort inequality (effort related to obtaining food). So far, there are no indications that social organizations affect the behavior in a clear and consistent way.

\section{Variability}

Due to scarcity of reliable, non-anecdotal data, there is currently no indication whether animals show any sensitivity or variability with respect to anything one might call principles or rules of justice. In principle, all four candidate principles could be investigated: Need (e.g., in case of scarcity: Do social animals provide most of the food available to those who starve the most?), equality (e.g., when a food source is found: Does everybody get the same amount?), equity (e.g., In collective hunting, does the animal who did most of the work get most of the prey?), and desert (e.g., does the most dominant animal always get most of the food?). However, the measurement problems involved in investigating these scenarios are much more severe than in humans (i.e., whether the animals are able to discriminate different social situations and relate them to different principles) and there seem to be very few indications that any "principle of justice" is reliably displayed across social situations.

\section{Expression}

Most expressions of inequity aversion are of a type that is both affective and negative. Paradigmatically, an animal "complains" when it gets less than the others (see also above, "subject of justice concerns"). It would be interesting to establish whether there are more complex patterns among animals when distribution problems arise, e.g., positive encouragement of sharing or a concern for others getting a fair share. But the difficulties of dealing with non-linguistic subjects are hard to overcome when investigating this issue.

All things considered, we conclude that the "space for justice" is rather limited even for animals that display a complex social life and that we consider to be able to act intentionally or for reasons. The main problem is that justice in a familiar sense involves elements and aspects that are present in the rich human cultures of justice, yet either absent or rudimentary in animal societies. And this is partly because important features of a sense of justice require mental capacities that are difficult to credit animals with (See the "A Scheme for Analyzing Justice" and "Justice and Mental Capacities" sections). If justice is narrowed down to an emotional reaction in well-specified and restricted distributional settings, behaviors indicating inequity aversion are discernible. Yet, they are mainly self-regarding, and hence one cannot speak of a genuine sense of justice or fairness (see the "Analyzing the Animal Justice Debate" section). 


\section{Broader Implications of Animal Justice Research}

Research on social norms and morality in animals is predominantly undertaken within an evolutionary framework: One expects to "understand" human sociality and morality by speculating about its evolutionary origins, and comparisons with extant animals are supposed to support these evolutionary hypotheses. Such research may indicate which kinds of situations may have been selected for (attention to distributions) and which emotions are involved in the phylogenesis of a sense of justice. Furthermore, studies of justice in animals have a methodological value as they require analyzing justice with a view to developing experimental paradigms for agents that do not possess human conceptual and linguistic abilities.

In other words, this research has doubtlessly the potential to inform the philosophical debate on justice. But it also has cultural effects that go beyond the academic debates in, e.g., anthropology, moral psychology, or ethical theories about the "foundations" of human morality. Books like The Age of Empathy: Nature's Lessons for a Kinder Society (de Waal 2009) or Braintrust. What Neuroscience Tells us about Morality (Churchland 2011) target a broad audience with a specific message —namely, that being "good" is part of human nature. As the notion of what "good" actually means in these contexts can be rather controversial, it is of interest to reflect on the potential effects of such claims on our ordinary understanding of justice and on potential errors.

We detect at least two issues in that respect. The first is the understanding of justice that is promoted using this research: Given the methodological constraints of working with animals, experiments rely on equality as normative goal; e.g., in the mini-ultimatum game with chimpanzees, an "unfair" distribution is treated as an unequal one. As a result, there is the danger-less in the philosophical discussion than in the public discourse that is triggered by such research-of reducing the notion of justice to a very simple concept of distributive justice in local interactions. This may be in line with the present political discussion on global inequalities, promoting a normative goal that "everyone should get the same" (e.g., with respect to a person's ecological footprint). This simple notion of justice may, however, not reflect the complexity of current distribution problems occurring within the largescale cooperation of (partly) anonymous institutions.

The second point refers to the rationale for justice-namely, as an instrument for maintaining cooperation. The reasoning behind many evolutionary approaches to justice runs as follows: Justice in small-scale groups is a normative and motivational force which sustains cooperation within this group; and justice in small groups is often a matter of equality (Bowles and Gintis 2011). Accordingly, inequalities in a society undermine cooperation, and this is a reason to promote an equality-based understanding of justice. But this reasoning is inconclusive. It assumes that cooperation including all members is actually needed to establish and maintain a working society. This assumption may not always hold. Poverty often involves exclusion of sizeable minorities whose integration into the cooperation processes of a society is actually not needed from a functional point of view (these sub-cultures will then create their own networks of cooperation). Indeed, cooperation may even run more smoothly by excluding some minorities. As a result, cooperation cannot be 
invoked to justify inclusion of and justice toward such minorities. And regarding cooperation and harmony as the ultimate rationale for justice may have morally unacceptable consequences, namely of giving succor to exclusionary and inequitable policies.

This article has dealt exclusively with animals as subjects rather than objects of morality. The topic was whether animals are themselves capable of a sense of justice, rather than what justice demands from our treatment of animals. The two issues are intimately linked by an important philosophical tradition, namely contractualism. According to contractualists, the basis of morality in general and justice in particular is provided by an actual or potential agreement between equals. This suggests that we owe justice only to creatures that can reciprocate, and hence, on standard differentialist assumptions, to animals. Rawls came close to accepting this conclusion (1971, p. 512), and others have endorsed it wholeheartedly (e.g., Carruthers 1992, pp. 96-97).

Now, contractualism may be right to regard human interaction as the foundation of morality. And it may also be right to insist that certain aspects of morality apply only to creatures with whom we can interact cognitively, morally, and emotionally. But it errs in holding that this interaction must take the form of entering into some kind of agreement that is either explicit or at least explicable. And it also errs in assuming that this interaction must always be fully reciprocal. Finally, it is misguided to think that only creatures capable of some kind of interaction can be beneficiaries of moral consideration at all. Moral value can be an intrinsic feature of a creature, while nonetheless being a matter of degree (see Glock 2012b). Applying this to one of the results of the research on animal justice, we find the following: If primates do not display other-regarding inequity aversion, this disqualifies them from possessing a bona fide sense of fairness or justice, and exempts them from normative expectations to behave in a just manner toward others that would go along with possessing such a sense. Still, the fact that they do display self-regarding inequity aversion entails among other things that-everything else being equal-we should not treat them in an inequitable manner, i.e., treat different individuals unequally without due cause. That injunction remains in place even if the consequence of violating it is "only" frustration, envy, and resentment rather than a sense of righteous indignation.

Acknowledgments For comments and advice, we should like to thank Sarah Brosnan, David Dolby, Mark Rowlands, Markus Wild, and two referees.

\section{References}

Aristotle (1984a). Politics. In J. Barnes (ed.), The Complete Works of Aristotle: The Revised Oxford Translation, Vol. 2. Princeton: Princeton University Press.

Aristotle (1984b). Nicomachean Ethics. In J. Barnes (ed.), The Complete Works of Aristotle: The Revised Oxford Translation, Vol. 2. Princeton: Princeton University Press.

Baker, G. P., \& Hacker, P. M. S. (1984). Language, sense and nonsense. Oxford: Blackwell.

Bekoff, M., \& Pierce, J. (2009). Wild justice: The moral lives of animals. Chicago: University of Chicago Press. 
Bermúdez, J. (2009). Mindreading in the Animal Kingdom. In J. Lurz (Ed.), The philosophy of animal minds (pp. 145-164). Cambridge: Cambridge University Press.

Bicchieri, C. (2006). The grammar of society: The nature and dynamics of social norms. Cambridge: Cambridge University Press.

Bolton, G. E., \& Zwick, R. (1995). Anonymity versus punishment in ultimatum bargaining. Games an Economic Behavior, 10, 95-121.

Bowles, S., \& Gintis, H. (2011). A cooperative species: Human reciprocity and its evolution. Princeton: Princeton University Press.

Brandom, R. (2000). Articulating reasons. Cambridge/Mass: Harvard University Press.

Bräuer, J., \& Hanus, D. (2012). Fairness in non-human primates? Social Justice Research, 25(3). doi: 10.1007/s11211-012-0159-6.

Bräuer, J., Call, J., \& Tomasello, M. (2006). Are apes really inequity averse? Proceedings of the Royal Society B, 273, 3123-3128.

Bräuer, J., Call, J., \& Tomasello, M. (2009). Are apes inequity averse? New data on the token-exchange paradigm. American Journal of Primatology, 71, 175-181.

Brosnan, S. F. (2006). Nonhuman species' reactions to inequity and their implications for fairness. Social Justice Research, 19(2), 153-185.

Brosnan, S. F. (2011). A hypothesis of the co-evolution of cooperation and response to inequity. Frontiers in Neuroscience, 5, Article 43.

Brosnan, S. F. (2011b). Property in nonhuman primates. New Directions in Child and Adolescent Behavior, 132, 9-22.

Brosnan, S. F., \& de Waal, F. B. M. (2003). Monkeys reject unequal pay. Nature, 425, 297-299.

Brosnan, S. F., \& de Waal, F. B. M. (2012). Fairness in animals: Where to from here? Social Justice Research, 25(3). doi:10.1007/s11211-012-0165-8.

Brosnan, S. F., Newton-Fisher, N. E., \& van Vugt, M. (2009). A melding of the minds: When primatology meets social psychology. Personality and Social Psychology Review, 13(2), 129-147.

Brosnan, S. F., Schiff, H. C., \& de Waal, F. B. (2005). Tolerance for inequity may increase with social closeness in chimpanzees. Proceedings of Biological Sciences, 272(1560), 253-258.

Brosnan, S. F., Talbot, C., Ahlgren, M., Lambeth, S. P., \& Schapiro, S. J. (2010). Mechanisms underlying responses to inequitable outcomes in chimpanzees, Pan troglodytes. Animal Behavior, 79, 1229-1237.

Burkart, J. M., \& van Schaik, C. P. (2010). Cognitive consequences of cooperative breeding. Animal Cognition, 31(1), 1-19.

Camerer, C. (2003). Behavioral game theory: Experiments in strategic interaction. Princeton: Princeton University Press.

Carruthers, P. (1992). The animal issues. Cambridge: Cambridge University Press.

Christen, M. (2010). Naturalisierung der Moral? Abklärung des Beitrags der Neurowissenschaft zum Verständnis moralischer Orientierung. In J. Fischer \& S. Gruden (Eds.), Struktur der moralischen Orientierung (pp. 49-123). Münster: LIT-Verlag.

Churchland, P. (2011). Braintrust. What Neuroscience tells us about morality. Princeton: Princeton University Press.

Cohen, G. (1989). On the currency of egalitarian justice. Ethics, 99, 906-944.

Cohen, G. (1993). Equality of what? On welfare, goods, and capabilities. In M. Nussbaum \& A. Sen (Eds.), The quality of life (pp. 9-29). Oxford: Claredon Press.

De Waal, F. B. M. (1996). Good natured: the origin of right and wrong in humans and other animals. Cambridge, Mass: Harvard University Press.

De Waal, F. B. M. (2009). The age of empathy: Nature's lessons for a kinder society. New York: Harmony Books.

Dubreuil, D., Gentile, M. S., \& Visalberghi, E. (2006). Are capuchin monkeys (Cebus apella) inequity averse? Proceedings of Biological Sciences, 273(1591), 1223-1228.

Dworkin, R. (1981). What is equality? Part 2: Equality of resources. Philosophy \& Public Affairs, 10, 283-345.

Elster, J. (1992). Local justice: How institutions allocate scarce goods and necessary burdens. Cambridge: Cambridge University Press.

Falk, A., Fehr, E., \& Fischbacher, U. (2003). On the nature of fair behavior. Economic Inquiry, 41(1), $20-26$.

Falk, A., \& Fischbacher, U. (2006). A theory of reciprocity. Games and Economic Behavior, 54, 293-315. 
Fehr, E., \& Schmidt, K. M. (1999). A theory of fairness, competition, and cooperation. The Quarterly Journal of Economics, 114, 817-868.

Fiste, A. P. (1993). Structures of social life. The four elementary forms of human relations. New York: The Free Press.

Fletcher, G. E. (2008). Attending to the outcome of others: Disadvantageous inequity aversion in male capuchin monkeys (Cebus apella). American Journal of Primatology, 70(9), 901-905.

Frankfurt, H. (1987). Equality as a moral ideal. Ethics, 98, 21-42.

Fry, D. P. (2005). The human potential for peace: An anthropological challenge to assumptions about war and violence. Oxford: Oxford University Press.

Glock, H. J. (2009). Can animals act for reasons? Inquiry, 52, 232-254.

Glock, H. J. (2010). Does language require conventions? In P. Frascolla, D. Marconi, \& A. Voltolini (Eds.), Wittgenstein: Mind, meaning and metaphilosophy (pp. 85-112). Basingstoke: Palgrave.

Glock, H. J. (2011). Doing good by splitting hairs? Analytic philosophy and applied ethics. Journal of Applied Philosophy, 28, 225-240.

Glock, H. J. (2012a). What is a theory of meaning? Just when you thought conceptual analysis was dead. Cahiers Ferdinand de Saussure, 65(2012), 51-79.

Glock, H. J. (2012b). Mental capacities and animal ethics. In K. Petrus \& M. Wild (Eds.), Animal minds and animal ethics. New York: Springer.

Glock, H. J. (2013). Animal minds: Philosophical and scientific aspects. In T. Racine \& K. Slaney (Eds.), The role and use of conceptual analysis in psychology. Palgrave: Basingstoke.

Hafner, C. L., \& Olson, J. M. (2003). An analysis of empirical research on the scope of justice. Personality and Social Psychology Review, 7(4), 311-323.

Hart, H. L. A. (1961/1997). The concept of law. Oxford: Clarendon Press.

Henrich, J. (2004). Animal behaviour: Inequity aversion in capuchins? Nature, 428(6979), 139. discussion 140.

Henrich, J., Fehr, E., \& Gintis, H. (Eds.). (2004). Foundations of human sociality: Economic experiments and ethnographic evidence from fifteen small-scale societies. Oxford: Oxford University Press.

Horn, C., \& Scarano, N. (Eds.). (2002). Philosophie der Gerechtigkeit. Texte von der Antike bis zur Gegenwart. Suhrkamp: Frankfurt a.M.

Horowitz, A. (2012). Fair is fine, but more is better: Limits to inequity aversion in the domestic dog. Social Justice Research, 25(2), 195-212.

Jensen, K., Call, J., \& Tomasello, M. (2007). Chimpanzees are rational maximizers in an ultimatum game. Science, 318(5847), 107-109.

Jensen, K., Hare, B., Call, J., \& Tomasello, M. (2006). What's in for me? Self-regard precludes altruism and spite in chimpanzees. Proceedings of the Royal Society B, 273, 1013-1021.

Kitcher, P. (2011). The ethical project. Cambridge MA: Harvard University Press.

Knobe, J., \& Nichols, S. (2008). Experimental philosophy. New York: Oxford University Press.

Krebs, A. (2000). Die neue Egalitarismuskritik im Überblick. In A. Krebs (Ed.), Gleichheit oder Gerechtigkeit (pp. 7-37). Frankfurt: Suhrkamp Taschenbuch Wissenschaft.

Kripke, S. (1982). Wittgenstein on rules and private language. Oxford: Blackwell.

Liebig, S. (2010). Warum ist Gerechtigkeit wichtig? Empirische Befunden aus den Sozial- und Verhaltenswissenschaften. In D. Fetchenhauer, N. Goldschmidt, S. Hradil, \& S. Liebig (Eds.), Warum ist Gerechtigkeit wichtig? (pp. 10-27). München: Roman Herzig Institut.

Marriott, B. M., \& Salzen, E. A. (1979). Food-storing behavior in captive squirrel monkeys (Saimiri sciureus). Primates, 20(2), 307-311.

Musschenga, A. W. (2005). Empirical ethics, context-sensitivity, and contextualism. Journal of Medicine and Philosophy, 30, 467-490.

Narvaez, D., \& Lapsley, D. (2005). The psychological foundations of everyday morality and moral expertise. In D. Lapsley \& C. Power (Eds.), Character psychology and character education (pp. 140-165). Notre Dame: University of Notre Dame Press.

Neiworth, J. J., Johnson, E. T., Whillock, K., Greenberg, J., \& Brown, V. (2009). Is a sense of inequity an ancestral primate trait? Testing social inequity in cotton top tamarins (Saguinus oedipus). Journal of Comparative Psychology, 123(1), 10-17.

Nozick, R. (1974). Anarchy, state and utopia. Oxford: Basil Blackwell.

Pierce, J., \& Bekoff, M. (2012). Wild justice redux: What we know about social justice in animals and why it matters. Social Justice Research, 25, 122-139.

Povinelli, D., \& Vonk, J. (2006). We don't need a microscope to explore the chimpanzee's mind. In S. Hurley \& M. Nudds (Eds.), Rational animals? (pp. 385-412). Oxford: Oxford University Press. 
Price, S. A., \& Brosnan, S. F. (2012). To each according to his need? Variability in the responses to inequity in non-human primates. Social Justice Research, 25(2), 140-169.

Rabin, M. (1993). Incorporating fairness into game theory and economics. American Economic Review, $83,1281-1302$.

Range, F., Horn, L., Viranyi, Z., \& Huber, L. (2009). The absence of reward induces inequity aversion in dogs. Proceedings of the National Academy of the Sciences USA, 106(1), 340-345.

Range, F., Leitner, K., \& Virányi, Z. (2012). The influence of the relationship and motivation on inequity aversion in dogs. Social Justice Research, 25(2), 170-194.

Rawls, J. (1971/2005). A theory of justice. Cambridge, MA: Belknap Press of Harvard University Press.

Roemer, J. (1998). Equality of opportunity. Cambridge, Mass.: Harvard University Press.

Scarano, N. (1998). Der Gerechtigkeitssinn. In O. Höffe (Ed.), John Rawls. Eine Theorie der Gerechtigkeit (pp. 231-249). Berlin: Akademie Verlag.

Searle, J. (1997). The explanation of cognition. In J. M. Preston (Ed.), Thought and language (pp. 103-126). Cambridge: Cambridge University Press.

Sen, A. (1992). Inequality reexamined. Oxford: Claredon Press.

Silberberg, A., Crescimbene, L., Addessi, E., Anderson, J. R., \& Visalberghi, E. (2009). Does inequity aversion depend on a frustration effect? A test with capuchin monkeys (Cebus apella). Animal Cognition, 12(3), 505-509.

Skitka, L. J. (2012). Cross-disciplinary conversations: A psychological perspective on justice research with non-human animals. Social Justice Research, 25(3). doi:10.1007/s11211-012-0161-z

Skitka, L. J., \& Crosby, J. F. (2003). Trends in the social psychological study of justice. Personality and Social Psychology Review, 7(4), 282-285.

Smith, P., \& Silberberg, A. (2010). Rational maximizing by humans (Homo spaiens) in an ultimatum game. Animal Cognition, 13, 671-677.

Sorabji, R. (1994). Animal minds and human morals. London: Routledge.

Takimoto, A., \& Fujita, K. (2011). I acknowledge your help: capuchin monkeys' sensitivity to others' labor. Animal Cognition, 14(5), 715-725.

Takimoto, A., Kuroshima, H., \& Fujita, K. (2010). Capuchin monkeys (Cebus apella) are sensitive to others' reward: an experimental analysis of food-choice for conspecifics. Animal Cognition, 13(2), 249-261.

Tomasello, M. (2009). Why we cooperate. Cambridge/Mass: MIT Press.

Tomasello, M., \& Call, J. (1997). Primate cognition. Oxford: Oxford University Press.

Tomasello, M., \& Call, J. (2006). Do chimpanzees know what others see-Or only what they are looking at? In S. Hurley \& M. Nudds (Eds.), Rational animals (pp. 371-384). Oxford: Oxford University Press.

Van Wolkentet, M., Brosnan, S. F., \& de Waal, F. B. M. (2007). Inequity responses of monkeys modified by effort. Proceedings of the National Academy of the Sciences USA, 104(47), 18854-18859.

Vlastos, G. (1971). Justice and happiness in the Republic. In G. Vlastos (Ed.), Plato: A collection of critical essays II (pp. 66-95). New York: Garden City.

Von Wright, G. H. (1963). Norm and action. London: RKP.

Walzer, M. (1983/2006). Sphären der Gerechtigkeit [orig: Spheres of Justice]. Frankfurt, New York: Campus Verlag.

Wynne, C. D. (2004). Animal behaviour: fair refusal by capuchin monkeys. Nature, 428(6979), 140. discussion 140.

Hurley, S., \& Nudds, M. (Eds.). (2006). Rational animals? Oxford: Oxford University Press.

Yamagishi, T., Horita, Y., Takagishi, H., Shinada, M., Tanida, S., \& Cook, K. S. (2009). The private rejection of unfair offers and emotional commitment. Proceedings of the National Academy of the Sciences USA, 106(28), 11520-11523.

Yamamoto, S., \& Takimoto, A. (2012). Empathy and fairness: Psychological mechanisms for eliciting and maintaining prosociality and cooperation in primates. Social Justice Research, 25(3). doi: 10.1007/s11211-012-0160-0. 